\title{
MI DESEO ES LA LEY. LOS DERECHOS DEL HOMBRE SIN NATURALEZA
}

\section{Grégor Puppinck}

Trad. F. Montesinos y M. Montes. Madrid: Ediciones Encuentro, 2020, 288 páginas.

Solo el individuo es necio; la especie es siempre sabia. Edmund Burke

Uno de los fenómenos más destacados y manifiestos de nuestro tiempo en el plano del pensamiento práctico-normativo (ética personal y social, derecho, política) radica en la difusión extendida y agresiva de un conjunto de ideas (en rigor y expresándolo con precisión, de una "ideología") que ha sido denominado como "ideología de género", "derechos de autonomía”, "derechos transhumanos", "ideología progresista” y varios calificativos más. Pero lo más notable es que estas ideas no solo aparecen en publicaciones, reuniones sectarias y cátedras varias, sino que, a fuerza de la militancia y la presión de sus partidarios, han llegado a introducirse en el derecho positivo de algunos países, en la jurisprudencia de tribunales internacionales y en las directivas pedagógicas de colegios y universidades.

Pero, además, también llama fuertemente la atención la escasa controversia que ha generado ese conjunto de ideas ("ideologías") en los grupos sociales y científicos que son sus opositores, que abordan las cuestiones práctico-normativas con mayor rigor y acribia teorética, remitiéndose a la experiencia de las que Aristóteles denominaba "cosas humanas" para fundamentar sus apreciaciones y valoraciones y, además, hacen uso riguroso de la lógica y la metodología científica. No obstante esto último, en los años recientes han aparecido algunos volúmenes que, desde la perspectiva del realismo, la objetividad y el rigor metodológico, han cuestionado meticulosa y sistemáticamente las pretensiones de las mencionadas ideologías; entre ellos, es posible enumerar sintéticamente Marion-ética. Los expertos de la ONU imponen su ley de Margerite A. Peeters, Bioética ¿El hombre contra el hombre? de Jean-Fréderic Poisson, Del sexo al género 
de María Isabel Llanes, Los discursos sobre el género de Ángela Aparisi Miralles y varias otros, especialmente el que se comentará aquí en su versión española, Les droits de l'homme dénaturé de Grégor Puppinck.

\section{El libro a analizar}

Este último libro, escrito por un antiguo profesor de la Universidad de Estrasburgo, director del Centro Europeo para la Ley y la Justicia y autor de varios volúmenes sobre temas de Bioética, Bioderecho y Filosofía Jurídica, tiene como hilo conductor la doctrina expresada -y a veces impuesta- en numerosos fallos del Tribunal Europeo de Derechos Humanos, fallos en los que se resume y se fuerza jurídicamente el cumplimiento de las exigencias de la "ideología de género" y de los denominados "derechos de autonomía" o bien "derechos transhumanos". Esto último le atribuye un innegable rigor a la argumentación desarrollada en el libro, toda vez que no remite, para exponer los contenidos ideológicos que cuestiona, a obras dispersas y de dudosa justificación, sino a la jurisprudencia oficial de una institución jurídica de la Unión Europea.

Siguiendo principalmente la deriva de estos y otros textos judiciales, aunque también una bibliografía amplia y pertinente, el autor comienza su exposición de la versión "desnaturalizada" de los derechos humanos describiendo de qué modo, inmediatamente después de la Segunda Guerra Mundial, un grupo de políticos y pensadores, muchos de ellos de raigambre cristiana, elaboraron, en el seno de la Organización de las Naciones Unidas recientemente creada, la denominada Declaración Universal de los Derechos Humanos, emitida en 1948 con el intento de establecer un límite relativamente seguro contra la inhumanidad de las ideologías nazi y comunista, que habían depredado a Europa en los años precedentes.

La intención de estos intelectuales era contestar las mencionadas ideologías desde una perspectiva "personalista", es decir, desde una concepción del hombre centrada en la noción de persona. Escribe Puppinck:

La persona es un ser encarnado, posee una espiritualidad y una comunidad natural. No es ni el Hombre abstracto de las Luces, ni el ciudadano de la república, ni el individuo-engranaje de la sociedad colectivista, ni es tampoco el individuo-autosuficiente de las sociedades liberales. La persona humana es un individuo re-humanizado, revestido de la naturaleza humana. (p. 40)

Y un poco más adelante agrega que 
la originalidad de los personalistas en el seno del pensamiento católico consiste en estimar que la sociedad está subordinada a la persona [...] ya que la persona es la única criatura creada por Dios por sí misma y a su imagen. (p. 41)

Y de este carácter creatural del hombre se sigue la dignidad elevada que corresponde a la persona, y en la que se encuentra el fundamento de los derechos humanos de la Declaración de 1948.

\section{La dignidad humana}

Ahora bien, el principal problema que se planteó poco después de la Declaración tuvo una de sus raíces en el carácter ambiguo con el que en general se ha hablado, y aún se habla, de la "dignidad humana". En efecto, para la concepción clásico-cristiana del hombre, la dignidad propia e intrínseca de la persona humana radica en el carácter racional y libre de su naturaleza, que supone una participación eminente en el Ser subsistente por sí mismo. Escribe el autor:

La dignidad de la persona humana expresa simplemente el valor de lo que distingue y sitúa al hombre por encima de las otras criaturas, a saber: su razón y su libertad, es decir, la posesión de un "espíritu”. Aristóteles enseña que el hombre es el mejor entre los seres vivos. (p. 52)

Y a continuación Puppinck remite a las ideas de los principales representantes de la concepción clásica del hombre, la ética y el derecho: Cicerón, San Agustín, Tomás de Aquino y, entre los contemporáneos, Thomas De Koninck.

Como consecuencia de esa noción de la dignidad de la naturaleza humana, vivir bien significa propiamente vivir conforme a la naturaleza, realizando de modo razonable los bienes que se siguen de ella. Afirma el autor que

esta moral es natural, porque deriva de la naturaleza humana: ella es la vía, el "camino recto" por el que la persona realiza su ser, su naturaleza humana, de manera cabal: ella es la "ley moral natural", la "ley grabada en los corazones" [y] accesible a la razón [...]. Al observar esta ley, la persona se consuma en sí misma y en ella encuentra su bien. (p. 57)

De este modo, esta concepción de la naturaleza y de la dignidad humana permite fundamentar y establecer sólidamente el contenido de los derechos humanos, así como su universalidad, objetividad y finalidad.

Ahora bien, en contraposición a esta visión clásica y cristiana del hombre 
y de sus derechos existe otra, cuyo origen remoto el autor lo coloca en la tradición gnóstica, en las ideas de Pico della Mirandola, en los planteos del canciller Francis Bacon, pero sobre todo en las ideas evolucionistas formuladas por Spencer y Darwin. Escribe Puppinck:

La formulación de Spencer y de Darwin en el siglo XIX, de la teoría de la evolución por la selección de los más aptos permitió a este pensamiento [antinaturalista] realizar la síntesis entre el discurso científico y el gnóstico, sobre una base materialista y con una perspectiva progresista [...]. Según esta síntesis, el espíritu humano sería una propiedad emergente brotada de la materia, la cima de un proceso de evolución que tiende a elevarse sin fin espiritualizándose cada vez más. (p. 61)

Esta hipótesis (parece un poco presuntuoso denominarla "teoría") fue asumida y desarrollada por Julian Huxley, quien en 1946 se hizo cargo de la dirección general de la UNESCO, desde donde publicó un manifiesto en el que propone la adopción de un "humanismo científico universal", contrario a todo lo sobrenatural y fundado en la evolución de matriz darwiniana. Según este "humanismo" (o, mejor, "transhumanismo"), una nueva versión de la dignidad del hombre estaría fundada en el desarrollo de la evolución biológica de la humanidad, que se orientaría hacia la liberación del intelecto del seno de la materia. De este modo, el hombre se iría desprendiendo de las cadenas de la naturaleza y emancipando a la mente de las cadenas de una ética realista que lo tiene sojuzgado a formas superadas evolutivamente de la humanidad.

Por supuesto que esta concepción supone que Dios no existe, que la naturaleza humana tampoco y que "el hombre sacaría de sí mismo su propia dignidad y esta estaría a la medida de su grado de espiritualización [o, mejor, mentalización subjetiva], es decir, de auto-extracción desde la materia: esta dignidad no conocería ningún límite" (p. 62) y el hombre podría alcanzar cuotas infinitas de mentalización y autodisposición. Por otra parte, conviene recordar que Huxley, notorio dualista en materia antropológica, fue vicepresidente de la British Eugenics Society, por lo que el eugenismo era uno de los núcleos centrales de su pensamiento. Y respecto a la temática de los derechos humanos, la concepción de Julian Huxley es radicalmente diversa de la pensada por los redactores de la Declaración de 1948, ya que al no existir ni Dios ni la naturaleza humana universal, el hombre individual será el encargado de autoproclamar sus propios derechos: él se reconoce como señor de su definición y sus contenidos dependen sin límites de la autonomía de su voluntad. 


\section{El desprecio de la naturaleza humana}

Resumiendo lo dicho hasta ahora, Puppinck afirma que

la cultura occidental ha acabado por salir vencedora sobre el colectivismo de las antiguas repúblicas soviéticas, pero, una vez roto el equilibrio de la Guerra Fría, los derechos humanos [de la ONU] no han sido capaces de preservarnos de los excesos inversos del individualismo. Contracepción, aborto, divorcio, pornografía, eutanasia, homosexualidad, eugenismo: todas estas prácticas, ampliamente prohibidas en la posguerra, son ahora derechos, y su crítica, algo prohibido. (p. 88)

En síntesis, esta corriente de ideas que fundamenta los derechos solo en las simples opciones individuales, en lugar de reconocerlos en la realidad práctico-moral, los convierte en un mero instrumento para la realización de los caprichos de minorías activas y turbulentas, despreciando la trascendencia ontológica y la naturaleza humana y sus bienes propios, y ha conducido a un vaciamiento de la idea de derechos naturales (o humanos) propuesta por la ética clásico-cristiana y a su sustitución por unas exigencias que resultan inhumanas por su contraposición radical al modo propio de ser del hombre y a las líneas perfectivas que de él se siguen objetivamente.

Luego de estas consideraciones, el autor estudia con especial acribia el proceso por el cual el Tribunal Europeo de Derechos Humanos, cooptado por una legión de posmarxistas, evolucionistas, nihilistas y demás militantes revolucionarios, ha ido desnaturalizando los derechos contenidos en la Declaración de 1948, sustituyéndolos por otros, fruto de la soberanía y autoafirmación del individuo y de la evolución de las especies. Para lograr este objetivo, los integrantes de la mayoría de ese tribunal han recurrido a una concepción expandida y profundizada de lo que denominan "vida privada", en la que incluyen todos los antojos humanos, por extravagantes que sean, y que por esta mera inclusión pasan a ser el objeto de derechos humanos de la nueva generación. Escribe Puppinck:

A medida que se extiende el campo de la vida privada la moralidad de los actos que esa vida cubre con su púdico velo [que en realidad son prácticamente todos los actos humanos] ya no puede ser apreciada de una manera objetiva [...] sino solo subjetivamente: en relación con la voluntad del sujeto. La moralidad de un "acto privado", ya no depende de su finalidad (objetiva), es decir, de su participación en un bien mayor que él, sino en su origen (subjetivo), o sea, de la voluntad del que lo realiza. (p. 115) 
Y, además, estos derechos, que originariamente eran defensivos, ahora se han vuelto ofensivos: ya no sirven solo para proteger a las personas de los abusos del estado totalitario, sino fundamentalmente para liberar a las personas de los límites de su naturaleza e incrementar su poder. Según el autor,
esta extensión del poder de los individuos tiene su fuente en el corazón de la vida privada, en el respeto a la voluntad individual [absoluta], es decir, de la "autonomía” y asume la forma de una multitud de nuevos derechos subjetivos, que corresponden a otros tantos deseos. (p. 121)

A continuación, Puppinck analiza y refuta la idea de cada uno de estos "nuevos derechos", comenzando por el que denomina "derecho matriz a disponer de su propio cuerpo" y continuando con el "derecho a morir voluntariamente", el "derecho al aborto", el "derecho a practicar la eutanasia a terceros", el "derecho a la libertad sexual", el "derecho al hijo", el "derecho a la procreación médicamente asistida", a la "gestación subrogada", a la "homoparentalidad" y así sucesivamente.

Estos mal denominados "derechos humanos" no son como los defendidos por la tradición clásica y la Declaración de 1948, que constituían garantías de la humanización del hombre conforme a su naturaleza, sino que le ofrecen al individuo el poder de negar esa naturaleza, la vida, el cuerpo, la familia, la religión, la moral objetiva y las tradiciones. Por ello, estos "derechos" no son solo nihilistas, sino que además son narcisistas y violentos y se pretende imponerlos por la fuerza del derecho y del Estado. "Para estos derechos -escribe el autor- el lenguaje de los derechos humanos no es más que el disfraz social de la voluntad de poder" (p. 165). Voluntad de poder que se ejerce por quien aparece como el nuevo soberano: el individuo desvinculado y omnipotente, que se construye a sí mismo conforme a las exigencias de su voluntad absolutamente autónoma y de un poder liberado de todo límite o condicionamiento.

\section{La antropología transhumanista}

De todo esto se sigue que los nuevos derechos -ya que todo derecho supone una concepción del hombre que la sostiene- se fundan en una concepción transhumanista, es decir, ordenada a la transformación y dominación del hombre por medio de la técnica. Puppinck sostiene: 
El transhumanismo es una ideología que, como el cientificismo del que procede, no se debe confundir con la ciencia: es un cientificismo prometeico dotado de nuevas tecnologías. Los profetas del transhumanismo prometen una transformación de la humanidad mediante el retroceso de la muerte y de la enfermedad, la mejora de las capacidades físicas y cognitivas, y la hibridación del hombre con la máquina. De este modo el hombre podría trascenderse a sí mismo, liberarse de la naturaleza recibida y, como una mariposa que sale del capullo, llegar a ser poshumano. (p. 195)

Dicho en otras palabras, se trata de la propuesta de una manipulación infinita (genética, quirúrgica, mecánica, química, etc.) y arbitraria del ser humano por el mismo hombre.

En el ámbito de los derechos humanos, este transhumanismo se manifiesta de varias maneras, en especial en la promoción del evolucionismo "progresista”, la rehabilitación del eugenismo, el abandono de la finalidad terapéutica de la medicina y su sustitución por objetivos de manipulación humana, la transexualidad ilimitada y, en definitiva, en la promoción de un Hombre Nuevo, muy a gusto del Jesuita Pierre Teilhard de Chardin, entusiasta promotor del transhumanismo (p. 200). Afirma Puppinck:

El hombre se constituye él mismo tanto psíquica (dimensión subjetiva) como físicamente (dimensión objetiva). Lo que subsiste de la criatura natural que fue la persona ya no es más que un material a partir del cual crear el hombre nuevo. [Y] Los derechos humanos tienen así la capacidad de integrar las modificaciones impresas en el ser humano por las tecnologías en su representación social. Los derechos humanos pueden digerir estos artificios; los normalizan regulándolos. (p. 217)

Pero, en rigor, esta manipulación transhumanista validada por los nuevos derechos humanos resulta ser en definitiva un instrumento de alienación del hombre, tanto en la dimensión individual como en la colectiva. En la primera,

el individualismo tiene como consecuencia necesaria e inevitable el refuerzo del estado, al que corresponde imponer la coexistencia de los individuos. Pero esta influencia ya no es reductible a la acción del estado, como en los tiempos de los totalitarismos estatales; ahora es obra de una red compleja que une los servicios públicos y privados, la administración [los organismos internacionales] y las empresas comerciales [...]. Así, por una aparente paradoja, cuanto más se individualizan las personas y más se integran en la nueva sociedad, menos independientes son [...]. De este modo, la búsqueda de la autonomía conduce a la alienación. (p. 221) 
Esto, en especial a través de la represión de las conciencias y la imposición, a veces violenta, de la nueva moral transhumanista.

Y en el plano colectivo, el predominio de estos "nuevos" derechos humanos lleva a una depreciación de la política, aun de la democrática, ya que los contenidos del derecho dejan de ser establecidos por las instituciones políticas del Estado nacional para pasar a ser impuestas por los tribunales internacionales, las comisiones de la ONU o los funcionarios encargados de la supervisión de la vigencia de los derechos transhumanos. De este modo, ya no queda nada en manos del "pueblo" y de los Estados, y la moral y el derecho resultan manejados por una "red global [que] garantiza también, en la medida de lo posible, la gobernanza moral mundial, a ejemplo de las instancias de gobernanza financiera, con las que comparte la doxa (opinión) liberal supranacional” (p. 248).

\section{Conclusiones del libro}

Puppinck concluye su libro proponiendo una resistencia política nacional contra la dictadura de la red moral mundial, resistencia de la que pone varios ejemplos exitosos, entre los que se puede destacar la denuncia del primer ministro británico David Cameron ante el Consejo de Europa, en la que afirmó que había llegado el momento de revisar el funcionamiento del Tribunal Europeo, en razón de su excesivo activismo que lo alejaba de su finalidad originaria, denuncia que fue apoyada por varios altos funcionarios británicos. Y el propio presidente del Tribunal Europeo ha sostenido que es necesario poner en tela de juicio la autoridad de ese Tribunal, a causa de su "pretendido activismo judicial, que excede los límites de sus competencias jurisdiccionales, rebasando la democracia nacional y derrocando las decisiones nacionales" (p. 269).

Por otra parte, el autor pone de relieve la grave insuficiencia de los derechos individuales al momento de considerar el bien humano, ya que suponen una radical incapacidad de pensar ese bien más allá del bien particular y en términos de bienes comunes. De este modo,

todos los otros bienes que tienen su fuente fuera de los individuos les quedan extraños, inconcebibles e indefendibles; peor aún, se presumen enemigos de la libertad [...]. Ahora bien, existen muchos bienes más allá del individuo [...]. Estos bienes [comunes] superan al individuo, a menudo preexisten a él y le sobreviven. El individuo los posee en la medida en que participa de ellos [...]; la experiencia enseña que la acumulación indeterminada de bienes individuales no basta para componer estos bienes comunes, sino que tiende más bien a erosionarlos. Muy 
a menudo, nos encontramos solos frente a nuestra propia autonomía, incapaces de determinar lo que es bueno para nosotros, ni de participar en un bien más allá de nosotros mismos. (p. 271)

Y termina sosteniendo que es necesario retornar a la apelación a la naturaleza humana y sus bienes propios para reconstruir una ética y un derecho a la medida del hombre. Para ello, es necesario para los seres humanos

\begin{abstract}
volver a descubrirse como parte de un todo [que] introduce una modalidad de humildad y conduce a pensar, en el orden considerado, en términos de bienes mejor que de derechos y a renunciar a su falsa libertad egodeterminada, para asumir positivamente la propia responsabilidad con respecto a los otros [...]. Este deseo [de participar en un todo] atestigua, frente a las desmesuras, la persistencia de la naturaleza humana; más aún, exige que no sea tanto el hombre el que se adapte a la evolución de su entorno, sino a la inversa, a fin de respetar la humanidad inmutable que es el hombre. (p. 274)
\end{abstract}

\title{
6. Algunas observaciones
}

Dentro de la brevedad que exigen las notas bibliográficas, corresponde hacer algunas observaciones puntuales sobre este libro rico, interesante y enormemente actual. La primera, de carácter formal, se refiere al título que se le ha puesto en la traducción española; la traducción literal del título francés es Los derechos del hombre desnaturalizado, que corresponde perfectamente con el contenido del libro, además de ser académicamente correcto y suficientemente ilustrativo. Ahora bien, se ha optado, probablemente por razones comerciales, por Mi deseo es la ley, que es prácticamente el mismo que se le puso en la Argentina al western Lawman de 1971, protagonizado por Burt Lancaster, cuya temática no tiene, obviamente, nada que ver con la del libro. Hubiera sido mejor optar por un título menos cinematográfico, más parecido al original y más académico.

La segunda observación, de carácter más sustantivo, se refiere a que el autor pareciera limitarse, al presentar los orígenes filosóficos del transhumanismo y de la concepción poshumana de los derechos, a los pensadores evolucionistas originarios (Darwin y Spencer), así como a algunos de sus seguidores contemporáneos, en especial Julian Huxley. Es cierto que estos autores han tenido su parte importante en la constitución de la ideología transhumanista, pero también resulta conveniente recordar que ha habido varias otras escuelas filosóficas que han efectuado contribuciones importantes a esa línea de pensamiento. Entre ellas es posible enumerar a los seguidores de David Hume (Alfred Ayer, 
Charles Stevenson, John Mackie), que establecieron la imposibilidad de un conocimiento racional y objetivo de la ética; los positivistas-utilitaristas, continuadores de Jeremy Bentham y John Austin, que contestaron la existencia de "absolutos morales" y de un derecho natural, aceptando solo razonamientos consecuencialistas; las diferentes variedades del marxismo: el soviético, el estructuralista, el analítico, el gramsciano del "uso alternativo del derecho", etc.; los posestructuralistas franceses, deudores de Nietzsche y encabezados por Michel Foucault; y varias corrientes más. Es verdad que no se puede saberlo todo, al menos bien, pero queda pendiente la tarea de estudiar específicamente la contribución de estas otras escuelas de pensamiento al desmantelamiento del humanismo cristiano de occidente.

\section{Balance conclusivo}

Pero más allá de estas observaciones marginales, es necesario concluir que se está en este caso en presencia de un libro de un especial interés y actualidad, ya que aborda uno de los temas más decisivos y determinantes de la vida humana contemporánea y del futuro del hombre y su aventura sobre la Tierra. Y, además, ese abordaje se realiza de un modo sistemático y riguroso, con argumentaciones válidas y concluyentes que conducen a conclusiones fundadas y convincentes. Resultan especialmente pertinentes las referencias precisas a las resoluciones de la Comisión Europea de Derechos Humanos, así como a los fallos del Tribunal Europeo de Derechos Humanos, la Corte Interamericana de Derechos Humanos, la Corte Suprema de los Estados Unidos y otras más, lo que otorga un rigor y una precisión indiscutibles a muchas de las afirmaciones sostenidas en el libro. Finalmente, resulta en especial destacable que todo el razonamiento desarrollado allí está expuesto con un coraje y un temple excepcionales, superador de las imposiciones de la corrección política y de las modas intelectuales, y con la decisión necesaria para exponer las conclusiones verdaderas sin temor a las presiones e imposiciones de la opinión preponderante. Esto trae a la memoria del autor de estas líneas la aguda frase de Gustave Thibon acerca de "la moda, esa tiranía de lo efímero que se ejerce sobre los desertores de la eternidad".

Sería de esperar que en lo sucesivo se publiquen muchos libros más como el presente, que abran la mente de los hombres contemporáneos, los convoquen a la acción inteligente, despierten su fortaleza y renueven su esperanza. Porque, como escribió alguna vez Jorge Luis Borges, "entre las cosas hay una, de la que 
no se arrepiente nadie en la Tierra; esa cosa, es haber sido valiente; siempre el coraje es mejor, la esperanza nunca es vana...”.

\section{Carlos I. Massini-Correas}

Universidad de Mendoza

carlos.massini@um.edu.ar 
